\title{
ARTICLE
}

\section{Integrated services and early intervention in the vocational rehabilitation of people with spinal cord injuries}

Julia Bloom ${ }^{1}$, Pat Dorsett ${ }^{2,3}$ and Vanette McLennan ${ }^{1,3}$

INTRODUCTION: The design was a narrative review. The objective of the study was to investigate the potential for early vocational rehabilitation (VR) interventions for people with spinal cord injury $(\mathrm{SCl})$ in overcoming barriers in returning to work, and to pinpoint factors contributing to effectiveness in early VR intervention for this population. The setting was at Queensland, Australia.

MATERIALS AND METHODS: Synthesis of the findings of a literature search of online databases ProQuest and CINAHL, using keywords relating to the employment situation and VR of people with $\mathrm{SCl}$. Themes were identified and analysed in accordance with the research objectives.

RESULTS: Despite increasing government commitment to the workforce and social participation of people with disabilities, Australians living with $\mathrm{SCl}$ have significantly diminished employment outcomes compared with the general population. Current VR approaches usually do not commence until some months post discharge, potentially missing a window of opportunity to preserve pre-existing employment or assist in vocational decision making. The review found that there are opportunities for enhancing VR service provision following $\mathrm{SCl}$, namely integrating the VR programme within the primary rehabilitation team thus facilitating early VR intervention.

DISCUSSION: Emerging evidence shows promising results for early intervention in VR; however, questions remain regarding ideal intervention approaches, and it is clear that further empirical investigation is required to support the use of early intervention models post SCl. The study was sponsored by Motor Accident Insurance Commission (MAIC).

Spinal Cord Series and Cases (2017) 3, 16042; doi:10.1038/scsandc.2016.42; published online 2 February 2017

\section{INTRODUCTION}

The benefits of employment to a person's physical, psychological and financial health are numerous and well-documented. Employment is associated with increased social integration, better physical and mental health and an improved quality of life. ${ }^{1,2}$ Subsequently, worker disability and absence from the workforce is associated with significantly diminished economic, health-related and psychosocial well-being. ${ }^{3}$ This raises concerns regarding the employment of people with disabilities in Australia, who have a significantly lower employment rate than people without disabilities. ${ }^{4}$ In fact, the OECD (2010) has rated Australia as having the 21 st lowest employment rate of people with disabilities out of 29 countries ranked.

Of particular interest to this review is the employment situation of people who have sustained a catastrophic injury, including spinal cord injury (SCl). Catastrophic injuries are generally defined as severe injuries to the spine, brain or surrounding skeletal structures. When not immediately fatal, these injuries often result in permanent impairment to a person's physical and cognitive functioning. ${ }^{5}$ These injuries have an immense impact on all areas of person's life, including the occupational domain. Lengthy absences from the workforce, the increased logistical complexity of working, potential discrimination and the need for physical and psychosocial support all represent potential barriers to returning to work following $\mathrm{SCl}$.

Emerging evidence suggests that vocational rehabilitation (VR) services occurring early within the primary rehabilitation process could work to overcome these barriers. ${ }^{6}$ Conventional rehabilitation approaches generally hold that vocational intervention is inappropriate in the primary rehabilitation phase because of the significant physical and psychological adjustments the person must undertake. Thus vocational intervention is typically delivered post discharge through referral to disability services or via insurerfunded private rehabilitation providers. Early intervention therefore refers to vocational services which commence pre-discharge, or during the primary/hospital rehabilitation phase.

This literature review will briefly explore the employment situation of people with $\mathrm{SCl}$ and the potential for an early intervention approach to overcome the barriers associated with return to work and thus the potential to enhance employment outcomes for this population.

\section{MATERIALS AND METHODS}

The search strategy used included searching the online databases, ProQuest and CINAHL, using the keywords 'employment', 'return to work', 'vocational rehabilitation', 'occupational rehabilitation' in combination with 'spinal cord injury' published between January 2004 and August 2015. Searching of citation lists and manual searching of relevant journals generated additional references. The search continued in an iterative manner, refining keywords and re-engaging with the literature until saturation was reached. Studies were selected for review if they specifically related to traumatic $\mathrm{SCl}$ sustained in adulthood, included employment or return to work as an outcome variable, or investigated early VR intervention programmes.

The search yielded 61 references. References were excluded on the basis of age and direct relevance to topic. Those included were grouped according to the following themes related to the research objectives: SCI and employment, $\mathrm{SCl}$ and early intervention VR, and current early VR

\footnotetext{
${ }^{1}$ School of Allied Health, Griffith University, Meadowbrook, Queensland, Australia; ${ }^{2}$ School of Human Services and Social Work, Griffith University, Meadowbrook, Queensland, Australia and ${ }^{3}$ Menzies Health Institute, Queensland, Australia. 
approaches. These themes were further developed and analysed in order to satisfy the research objectives.

\section{Spinal cord injury and employment}

As technology has improved, the life expectancy of people with $\mathrm{SCl}$ has steadily increased and with it has increased the push for effective vocational services to maximise economic and community engagement of this population. Despite this, employment outcomes remain diminished. Employment rate has traditionally been used as the primary outcome measure of both return to work (RTW) programmes post-SCl research investigating this area. ${ }^{7-10}$ Employment rate differs broadly between countries due to different cultural, economic and legislative environments, with estimates ranging between 15 and $60 \% .^{5}$ Recent literature regarding Australian employment rates for people who have sustained a SCl estimates median RTW rates between 21 and 35\%, compared with a general workforce participation rate of $65 \% .{ }^{11-13}$

Time to return to work following a $\mathrm{SCl}$ is lengthy; people often lose their jobs post $\mathrm{SCl}$ onset because they are away from work for significant periods of time while undertaking medical and physical rehabilitation and are often advised that they need time to adjust to their injury before considering returning to work. ${ }^{14-16}$ It can take years for a person to obtain new employment following a $\mathrm{SCl}$, with the interval between onset of $\mathrm{SCl}$ and paid employment being $\sim 4$ or 5 years. ${ }^{6,17,18}$

\section{The benefits of work}

Although it is accepted that working is generally beneficial for most people, evidence suggests that it is uniquely beneficial for people with $\mathrm{SCl}$. For example, Chapin and Holbert ${ }^{19}$ found that employed post-SCl participants reported more positive feelings, greater life satisfaction and a higher subjective quality of life than their unemployed counterparts. Furthermore, engaging in paid work is a way of remaining productive and therefore reinforcing self-efficacy and self-esteem. ${ }^{20}$ There is also evidence to suggest that working post $\mathrm{SCl}$ is associated with a longer, healthier life. ${ }^{21}$ This underscores the potentially damaging effects of allowing this population to 'slip through the cracks' of current VR service delivery models and highlights an opportunity for improving such services through the introduction of an early intervention component.

\section{Early intervention}

The primary rehabilitation models for people with $\mathrm{SCl}$ usually do not incorporate serious consideration for vocational options or long-term vocational goals, instead prioritising functional independence and social re-integration. ${ }^{22}$ This is despite the fact that work is viewed by people with $\mathrm{SCl}$ as being a central part of returning to a normal life. ${ }^{14,23}$ Conventional wisdom generally holds that vocational considerations are inappropriate in the primary rehabilitation phase due to the significant physical and psychosocial adjustment process a person must undertake.

Emerging research suggests, however, that this reasoning may be flawed; a United Kingdom study regarding RTW post SCl found that half of participants reported feeling ready to discuss employment during their initial hospital admission. ${ }^{16}$ Similarly, a Swedish study of young adults aged 20-34 who had sustained a SCl indicated that this population perceived themselves as ready to and capable of work, but required guidance in making vocational decisions and support in sourcing appropriate work experience or training. ${ }^{\text {? }}$

Those who do return to work early tend to return to their previous employer, ${ }^{16}$ and supportive employers have been recognised as promoting employment in this population. ${ }^{24}$ Early vocational intervention could preserve this relationship and maximise employer support through liaison with the employer and use of appropriate workplace supports. This is the most common pathway back into the workforce for those who achieve an earlier return. ${ }^{22}$ Cross-sectional research in the USA echoes these findings, with returning to the previous employer identified as a 'fast track' to RTW following a SCl. ${ }^{6}$ Furthermore, Krause et al. ${ }^{6}$ suggest that there is a limited time span in which to achieve this through capitalising on pre-injury skills and maintaining the occupational bond. These findings highlight an international service delivery gap and reframe the question of early intervention from 'how early is too early?' to 'how late is too late?'.

\section{Early intervention in other populations}

Studies with other catastrophic injury populations such as traumatic brain injury have suggested that the latency at which VR services are offered is an important factor in determining the long-term employment outcomes, with earlier service delivery being associated with improved vocational outcomes. ${ }^{25}$ For example, earlier placement in supported employment predicted a higher likelihood of RTW for people who have sustained a traumatic brain injury. ${ }^{26}$ In addition, an integrated primary and VR model, with early intervention as key feature, reported success in the rehabilitation of people with moderate to severe brain injuries with the authors concluding that early VR intervention appears to enhance employment outcomes through return to the previous employer. ${ }^{27}$ Taken together, these studies provide further evidence for the potential effectiveness of early intervention in enhancing the employment outcomes of people who have sustained a catastrophic injury including $\mathrm{SCl}$.

\section{Early intervention in practice}

Recent endeavours to address the question of early intervention in catastrophic injuries include the Lifetime Care and Support Authority's (LTCSA) 'In-Voc Pilot Programme' in which patients who had sustained a $\mathrm{SCl}$ within the previous 6 months were offered VR services in addition to their primary rehabilitation programme. ${ }^{11}$ Early results were promising, with $34.5 \%$ of participants engaging in paid employment at a median of 3 weeks post discharge, a rate which can be expected to increase over time. $^{22}$

Similar results have been found in New Zealand's Kaleidoscope Vocational Program upon which the In-Voc Programme was based. ${ }^{11}$ Implemented as part of a two-pronged approach to lifting the employment rate of people with $\mathrm{SCl}$, the Kaleidoscope programme incorporates commencing vocational intervention within 1 week of admission to the subacute rehabilitation facility. The Kaleidoscope programme has had significant success with post-SCl employment rates of $41 \%$, compared with an overall post-SCl employment rate of $13 \%$ prior to the implementation of the programme. ${ }^{28}$ Proponents of the programme indicate that early intervention is the main predictor of the programme's success. ${ }^{28}$

The two programmes share many similarities, including their underpinning philosophies, approach to rehabilitation and similar employment outcomes. Differences in timing of intervention could be attributed to systemic differences which influence the stage at which primary rehabilitation services commence; more integrated systems such as those in New Zealand may commence initial rehabilitation at the acute stage, whereas the more fragmented New South Wales system delays rehabilitation until subacute admission. This begs the question of whether intervention is 'the earlier the better', or whether there is a point in time where intervention is maximally effective.

\section{Benefits of early intervention}

Beyond enhancing employment outcomes, early vocational intervention may enhance broader rehabilitation outcomes through inspiring hope and enhancing motivation. For example, early consideration of vocational goals during the rehabilitation process communicates to clients that returning to work is not only possible, but likely. ${ }^{22}$ Evidence suggests that identifying RTW as a treatment goal enhances hope and motivation and in turn reinforces treatment adherence. ${ }^{14}$ Motivation is a strong predictor of VR employment outcomes generally, and evidence suggests that this is also the case within those with people who have sustained a SCI. ${ }^{14}$ Higher selfreported levels of motivation are associated with a greater likelihood of having ever worked following a $\mathrm{SCl}^{29}$ Hope also enhances coping and psychosocial adjustment. ${ }^{30}$ This was observed in NSW In-Voc programme of which early intervention was a feature: participants retained stable quality of life scores during a time when it would be expected to decrease. ${ }^{11}$

Early intervention may also assist in preventing the long-term financial disadvantage often associated with $\mathrm{SCl}$. These injuries have accompanying medical and assistive technology costs which are often not met by medical or welfare systems and this is exacerbated by long-term unemployment. ${ }^{31}$ Physical impairment combined with economic hardship may create a 'double disadvantage' in that this group is physically and socioeconomically handicapped by their injury. A shorter latency between the injury and employment appears to have a protective effect against this financial disadvantage and improves job retention over time, potentially enhancing lifelong financial health. ${ }^{6,32}$

This shorter latency could potentially be achieved through early vocational intervention. 
Challenges in early intervention

Although early intervention and integration of services within the primary rehabilitation programme appears to have many positive effects, the willingness of participants to engage in such a programme soon after their injury is variable. Qualitative research reveals varying levels of motivation, with some participants unwilling to approach topic of returning to work during a time of tremendous physical, psychological and interpersonal upheaval. ${ }^{16,33}$ This is congruent with the predominant thinking surrounding returning to work post $\mathrm{SCl}$ and has important implications for any model attempting to incorporate an early intervention approach, which must consider appropriate timing and assertiveness of intervention. Current early intervention approaches incorporate motivational interviewing in order to assess and work within the client's motivational state and potentially overcome this barrier. ${ }^{22}$ The attitudes and motivations of treating clinicians are just as vital as those of the clients to the success of early vocational intervention. Many clinicians may subscribe to traditional thought regarding $\mathrm{SCl}$ rehabilitation and may reject vocational intervention at such an early stage. One strategy to overcome this is integration of the VR professional within the primary rehabilitation team. This may foster cultural change within the team and significantly enhance client access to VR services. ${ }^{34}$

\section{Methodological considerations}

Rehabilitation success post $\mathrm{SCl}$ can be assessed in a multitude of ways, including employment rate, income and time taken to return to work. ${ }^{6,18,35}$ However, comparison of these measures is difficult due to pervasive methodological, sampling and definitional differences throughout the literature. Specific early intervention studies tend to utilise employment rate as the primary outcome measure due to its establishment as the "gold standard' measure of rehabilitation success. However, static point in time measures may under- or overestimate the actual long-term outcome of the study in question. In addition, employment rate is somewhat reductionist; it provides no information regarding long-term career outcomes following $\mathrm{SCl}$, job retention rates post $\mathrm{SCl}$, or how happy people are in their work post SCl.

A broader scope of outcome measures, including employment trajectories and job satisfaction would assist in completing the picture of post-SCl employment research. ${ }^{21,22}$ Data on job retention rates following $\mathrm{SCl}$ are relatively scarce as relatively little is known about workers' longterm career trajectories subsequent to their injuries. ${ }^{36}$ Evidence suggests that workers have difficulty sustaining long-term employment following their injury. ${ }^{36}$ This is due to a number of factors, including the onset of secondary health conditions, comorbid mental health issues, ageing or household responsibilities. ${ }^{36,37}$ Further research investigating the longterm career pathways of this population could identify the points at which support may be required, providing targets for intervention and thus enhancing lifespan career development.

Related to job retention is job satisfaction. Young and Murphy ${ }^{38}$ identified job satisfaction as a potential indicator of VR programme success, as well as highlighting its utility in resource allocation. Researchers suggested that unemployed participants dissatisfied with their vocational status were generally not performing highly active job searches and thus could be better supported through VR intervention to facilitate employment attainment. Young and Murphy ${ }^{38}$ also recommended that employed participants who are dissatisfied with their vocational situation could benefit from additional support to prevent withdrawal from the labour market. This indicates that job satisfaction has potential to inform future VR programmes and interventions.

Further to these findings, research indicates that some participants may accept work out of 'economic desperation', not necessarily employment which fully utilises a person's knowledge and skills. ${ }^{39}$ The resulting diminished job satisfaction could inflate employment lapse rates as consumers are disheartened by being physically unable to perform their preferred tasks. Hay-Smith and Dickson ${ }^{23}$ briefly touched on this issue with their phenomenological study into the meaning of work post SCl. One participant of this study alluded to this issue and stated that they had rejected a concrete job offer because it was a 'dumbed down' application of their skills (p.1441). Being given 'token' work which requires little training or skill is an issue emphasised by people in this population who report feeling insulted and belittled as a result of being assigned such tasks. ${ }^{23}$ Thus it appears that job satisfaction, or perceived potential for satisfaction, has a possibly mediating role in enhancing rehabilitation outcomes and facilitating employment post $\mathrm{SCl}$ and so should be investigated empirically.
Implications

The aim of this review was to explore the potential for early intervention to enhance the VR of people with $\mathrm{SCl}$ and to identify factors relating to the success of such programmes. People with this injury have specialised needs which are perhaps not being met by VR services, highlighting a service gap between primary and VR services.

The identification of the 'fast track' to return to work, and subsequent emerging support of this pathway represents an opportunity for rehabilitation counsellors. Liaison with the previous employer has traditionally not been undertaken during primary rehabilitation as this is beyond the scope of practice of the professionals involved. Contact with the previous employer would involve providing information regarding the injury and the likely resulting physical impairment, information regarding available workplace supports or incentives available to the employer, and a discussion about the availability of suitable work tasks for the employee. This highlights an opportunity for the involvement of vocational specialists, such as rehabilitation counsellors, whose niche skill set is typically underutilised within the primary rehabilitation context and whose professional management of this sensitive task could preserve jobs that would otherwise be lost.

Long-term career development considerations should be taken into account when developing enhanced vocational services models for people following a $\mathrm{SCl}$, as this population demonstrates reduced income, higher underemployment and earlier retirement than average. ${ }^{37,40}$ Existing VR services are generally insurer-driven, and usually terminate soon after employment is obtained with limited consideration of the person's ongoing career development.

Finally, an enhanced model of VR service provision following a SCl could be transferable to the broader catastrophic injury population. SCI may be accompanied by comorbid mental or cognitive health problems and people with these problems have been excluded from emerging models.2 This raises questions of inclusion. There is evidence to support early vocational intervention in people with a traumatic brain injury, suggesting that early and integrated services could support employment outcomes for a wide range of people. ${ }^{25}$

\section{CONCLUSION}

Clearly there is emerging evidence for the potential of early intervention in the VR of people following $\mathrm{SCl}$, and this warrants further investigation. Questions still remain, however, regarding the best timing of vocational intervention following a $\mathrm{SCl}$ and whether there is a need for continuing support from a long-term, career development perspective.

Future research should consider longitudinal investigation of career trajectories of people following $\mathrm{SCl}$ in order to form a comprehensive picture of this group's long-term employment situation and identify areas where support is necessary to preserve the initial success of early intervention VR programmes. In addition, more holistic outcome measures, including job satisfaction and job retention, could potentially inform as to the quality of return to work success.

\section{COMPETING INTERESTS}

The authors declare no conflict of interest.

\section{REFERENCES}

1 Murphy GC. Putting a vocational focus back into rehabilitation. Aust J Career Dev 2009; 18: 36-44.

2 The Royal Australasian College of Physicians and The Australasian Faculty of Occupational and Environmental Medicine. Realising the Health Benefits of Work, A Position Statement [Internet]. 2011 AFOEM. [cited 2016 Nov 10]. Available from: https://www.racp.edu.au/docs/default-source/advocacy-library/realising-thehealth-benefits-of-work.pdf.

3 Waddell G, Burton K. Is Work Good for Your Health and Well Being? Report. UK Department for Work and Pensions: London, UK, 2006.

4 Organisation for Economic Co-operation and Development. Sickness, disability and work: breaking the barriers, a synthesis of findings across OECD countries [Internet]. OECD Publishing [cited 2016 Nov 10], 2010 Available from: http://www.oecd.org/publications/sickness-disability-and-work-breaking-the-bar riers-9789264088856-en.htm. 
5 Piccenna L, Pattuwage L, Romero L, Lewis V, Gruen R, Bragge P. Optimising Return to Work Practices Following Catastrophic Injury. National Trauma Institute (NTRI) Forum: Australia, 2015. Accessed on 04 August 2015. Available at http://www. ntriforum.org.au/images/ntri_forum/Return_to_work_brief_doc_FINAL.pdf.

6 Krause J, Terza J, Saunders L, Dismuke C. Delayed entry into employment after spinal cord injury: factors related to time to first job. Spinal Cord 2010; 48: 487-491.

7 Bergmark L, Westgren N, Asaba E. Returning to work after spinal cord injury: exploring young adults' early expectations and experience. Disabil Rehabili 2011; 33: $2553-2558$.

8 Chan SKK, Man DWK. Barriers to returning to work for people with spinal cord injuries: a focus group study. Work 2005; 25: 325-332.

9 Cotner BA, Keleher J, O'Connor DR, Trainor JK, Ottomanelli L. The role of social networks for veterans with spinal cord injury in obtaining employment. Ann Anthropol Pract 2013; 37: 40-56.

10 Crisp R. Key factors related to vocational outcome: trends for six disability groups. J Rehabil 2005; 71: 30-37.

11 Johnston D, Cameron I. Evaluation of the INvoc pilot-early access to vocational rehabilitation services (for People with Spinal Cord Injury): Interim Report. Rehabilitation Studies Unit, Sydney Medical School, Sydney University: Sydney, NSW, Australia, 2014.

12 Victorian Neurotrauma Initiative. The economic cost of spinal cord injury and traumatic brain injury in Australia [Internet]. Access Economics, [cited 2016 Nov 10] 2009. Available from: https://www.tac.vic.gov.au/about-the-tac/our-orga nisation/research/tac-neurotrauma-research/vni/the20economic20cost20of20spi nal20cord20injury20and20traumatic20brain20injury20in20australia.pdf.

13 Young AE, Murphy GC. Employment status after spinal cord injury (1992-2005): a review with implications for interpretation, evaluation, further research, and clinical practice. Int J Rehabil Res 2009; 32: 1.

14 Fadyl JK, McPherson KM. Understanding decisions about work after spinal cord injury. J Occup Rehabil 2010; 20: 69-80.

15 Ferdiana A, Post MW, Hoekstra T, van der Woude LH, van der Klink JJ, Bültmann U. Employment trajectories after spinal cord injury: results from a 5-year prospective cohort study. Arch Phys Med Rehabil 2014; 95: 2040-2046.

16 Hills $L$, Cullen E. A study into the employment trends of individuals treated at a spinal cord injury centre... including commentary by Kennedy P. Int J Ther Rehabil 2007; 14: 350-355.

17 Berkowitz M. Spinal Cord Injury: an Analysis of Medical and Social Costs. Demos: New York, USA, 1998

18 Krause J. Years to employment after spinal cord injury. Arch Phys Med Rehabil 2003; 84: 1282-1289.

19 Chapin MH, Holbert D. Employment at closure is associated with enhanced quality of life and subjective well-being for persons with spinal cord injuries. Rehabil Couns Bull 2010; 54: 6-14.

20 Clifton S. Spinal cord injury and the joy of work. Scand J Disabil Res 2014; 16: 377.

21 Krause J, Saunders L, Acuna J. Gainful employment and risk of mortality after spinal cord injury: effects beyond that of demographic, injury and socioeconomic factors. Spinal Cord 2012; 50: 784-788.
22 Middleton JW, Johnston D, Murphy G, Ramakrishnan K, Savage N, Harper R et al. Early access to vocational rehabilitation for spinal cord injury inpatients. J Rehabil Med 2015; 47: 626-631.

23 Hay-Smith EJC, Dickson B, Nunnerley J, Anne Sinnott K. 'The final piece of the puzzle to fit in': an interpretative phenomenological analysis of the return to employment in New Zealand after spinal cord injury. Disabil Rehabil 2013; 35: 1436-1446.

24 Lloyd C, King R. Implementation of supported employment: what are the implications for clinical services? J Rehabil 2012; 78: 25-29.

25 Kendall E, Muenchberger H, Gee T. Vocational rehabilitation following traumatic brain injury: a quantitative synthesis of outcome studies. J Vocat Rehabil 2006; 25 : 149-160.

26 Babineau JL. The value of early placement in a supported employment program for individuals with traumatic brain injury. Work 1998; 10: 137-146.

27 Malec JF, Buffington ALH, Moessner AM, Degiorgio L. A medical/vocational case coordination system for persons with brain injury: an evaluation of employment outcomes. Arch Phys Medicine Rehabil 2000; 81: 1007-1015.

28 Perriam A. Wheels in work. Australia New Zealand Spinal Cord Society Conference 2008. Australia New Zealand Spinal Cord Society: Christchurch, New Zealand, 2008.

29 Krause J, Reed K. Barriers and facilitators to employment after spinal cord injury: underlying dimensions and their relationship to labor force participation. Spinal Cord 2011; 49: 285-291.

30 Dorsett P. The importance of hope in coping with severe acquired disability. Aust Soc Work 2010; 63: 83-102.

31 Munce SEP, Wodchis WP, Guilcher SJ, Couris CM, Verrier M, Fung K et al. Direct costs of adult traumatic spinal cord injury in Ontario. Spinal Cord 2013; 51: 64-69.

32 Mitchell JM, Adkins RH, Kemp BJ. The effects of aging on employment of people with and without disabilities. Rehabil Couns Bull 2006; 49: 157-165.

33 Ville I. Biographical work and returning to employment following a spinal cord injury. Sociol Health IIIn 2005; 27: 324-350.

34 Ottomanelli L, Goetz L, Suris A, McGeough C, Sinnott PL, Toscano R et al. Effectiveness of supported employment for veterans with spinal cord injuries: results from a Randomized Multisite Study. Arch Phys Med Rehabil 2012; 93: 740-747.

35 Paul C, Derrett S, McAllister S, Herbison P, Beaver C, Sullivan M. Socioeconomic outcomes following spinal cord injury and the role of no-fault compensation: longitudinal study. Spinal Cord 2013; 51: 919-925.

36 Hilton G. The Experience of Achieving a Successful Employment Outcome Following Traumatic Spinal Cord Injury: Pathways and Processes. AQA Victoria: Melbourne, Australia, 2014

37 Krause J, Dismuke C, Acuna J, Sligh-Conway C, Walker E, Washington K et al. Race-ethnicity and poverty after spinal cord injury. Spinal Cord 2014; 52: 133-138.

38 Young AE, Murphy GC. A Social psychology approach to measuring vocational rehabilitation intervention effectiveness. J Occup Rehabil 2002; 12: 175-189.

39 Ramakrishnan K, Mazlan M, Julia PE, Abdul Latif L. Return to work after spinal cord injury: factors related to time to first job. Spinal Cord 2011; 49: 924-927.

40 Brown $\mathrm{P}$, Johnson K. Aging with a disability and state vocational rehabilitation services. Work 2014; 48: 441. 